\title{
La garantía de presunción de inocencia del procesado en el procedimiento directo
}

The guarantee of the presumption of innocence of the defendant in the direct procedure

Merck Benavides-Benalcázar

ui.merckbenavides@uniandes.edu.ec

Universidad Regional Autónoma de los Andes, Ibarra

Ecuador

https://orcid.org/0000-0003-2771-1104

Nelly Belén Burgos-Vargas

di.nellybbv79@uniandes.edu.ec

Universidad Regional Autónoma de los Andes, Ibarra

Ecuador

https://orcid.org/0000-0002-2088-534X

Najely Anahí Carrillo-Vera

di.najelyacv39@uniandes.edu.ec

Universidad Regional Autónoma de los Andes, Ibarra

Ecuador

https://orcid.org/ 0000-0002-2078-3925

Recepción: 15 de septiembre 2021

Revisado: 25 octubre 2021

Aprobación: 15 de noviembre 2021

Publicación: 01 de diciembre 2021 


\section{Estimado Editor (a):}

En el Estado constitucional de derechos y justicia que actualmente nos encontramos, nuestros derechos fundamentales, como el principio de presunción de inocencia, deben adquirir un valor primordial y de esencial relevancia, puesto que es un bien jurídico invaluable, nuestra libertad como la vida, la inocencia, el honor y la integridad física, integran la personalidad del hombre que le permite transitar libremente por las calles, así el estado se encarga de cumplir y hacer cumplir con nuestros derechos y obligaciones, a fin de garantizar que los derechos humanos se practiquen en la sociedad. Al respecto, el derecho procesal penal es el sismógrafo de la Constitución política del Estado. Por ello es frecuente que en los textos se empleen conceptos como derechos fundamentales, derechos fundamentales procesales, derechos humanos, principios procesales, libertades públicas, garantías institucionales, entre otros conceptos, para referirse por lo general a lo mismo: las garantías procesales penales constitucionalizadas, (Roxin, 2003).

En este sentido, el proceso penal está revestido de diversas garantías de reconocimiento constitucional que, como se ha relevado, buscan no sólo otorgar al procesado un marco de seguridad jurídica, sino en última instancia mantener un equilibrio entre la búsqueda de la verdad material y los derechos fundamentales del imputado, los cuales constituyen un límite al poder punitivo estatal, cuya protección y respeto no pueden ser ajenos a una justicia penal contemporánea.

Por ello, la presunción de inocencia, es el derecho que tienen todas las personas, a que se considere a priori como regla general, que ellas actúan de acuerdo a la recta razón, comportándose de acuerdo a los valores, principios y reglas del ordenamiento jurídico, mientras un juez o jueza competente no adquiera la convicción, a través de los medios de prueba legal, de su participación y responsabilidad en el hecho punible determinado por una sentencia firme y fundada, obtenida respetando todas y cada una de las reglas del debido y justo proceso.

Al respeto, García Falconi (2011), al referirse básicamente sobre el derecho constitucional a la presunción de inocencia, dice: 
Es un derecho, que como fundamental debe ser preservado para cualquier persona, por cuanto se ve limitado por el cometimiento de una infracción penal, esa limitación está respaldada por una serie de garantías que señala la Constitución de la República, Los tratados internacionales de derechos humanos y las leyes. (p. 29)

Hay que señalar, que, en atención a este principio, el procesado no está obligado a presentar prueba alguna que demuestre su inocencia, y por el contrario ordena a las autoridades judiciales competentes, la demostración de culpabilidad del procesado; recordando que, para dictar sentencia condenatoria, según dispone el Código Orgánico Integral Penal (2014):

Artículo 5.3: Duda a favor del reo: la o el juzgador, para dictar sentencia condenatoria, debe tener el convencimiento de la culpabilidad penal de la persona procesada, más allá de toda duda razonable.

El principio constitucional de presunción de inocencia, exige que el procesado sea tratado como inocente en la sustanciación del proceso; esto es reconocer el derecho a permanecer en libertad durante el proceso, o sea a considerar que el procesado no puede ser sometido a una pena, y por tanto no puede ser tratado como culpable, hasta que no se dicte la sentencia firme de condena, esto constituye el principio rector para expresar los límites de las medidas de coerción procesal contra él; pues la presunción de inocencia es una garantía básica y vertebral del proceso penal, que constituye un criterio normativo del derecho penal sustantivo y adjetivo, descartando toda normativa que implique una presunción de culpabilidad y, establezca la carga al procesado de probar su inocencia por regla general, toda vez que en determinados delitos tipificados en el Código Orgánico Integral Penal (COIP), se reinvierte la carga de la prueba, especialmente en los delitos ambientales.

Por tal, hay que tener en cuenta, que el principio de presunción de inocencia, es la clave explicativa de todo el régimen de garantías procesales, de tal manera que la jueza o juez de garantías penales, debe motivar racionalmente su decisión al dictar una orden de prisión preventiva y el fiscal al solicitarla, especialmente al momento de valorar los elementos de convicción e indicios que establece el artículo 534 del COIP, para dictar la prisión preventiva. La presunción de inocencia, es una presunción iuris 
tantum o legal, es decir no es absoluta, puesto que las pruebas de cargo que se presentan por parte de la fiscalía o en su caso por el querellante, pueden dar con ella al traste, pero sólo queda desvirtuada definitivamente cuando se dicta sentencia condenatoria ejecutoriada. Esta presunción se aplica no solo en materia penal, sino también en el derecho administrativo sancionador. En este sentido, "si no se parte de la presunción de inocencia, no habría ninguna necesidad lógica del proceso" (Pérez y Cruz, 2016, p. 39). Por lo tanto, es el juez de garantías penales, quien debe señalar en la primera audiencia de flagrancia, el camino procesal, que corresponde al trámite de procedimiento directo; debiendo el juez, como segunda exigencia, señalar dentro de los diez días, la fecha para la realización de la audiencia final de juicio directo, precisamente porque lo que se busca es celeridad, para ello, le facilitará a la defensa del procesado el acceso al expediente físico o de modo informático, para que tenga el tiempo suficiente para preparar la defensa. Por otro lado, la presunción de inocencia representa una composición de manera doctrinal tal como lo cita Rodríguez Choconta de manera que menciona un principio general del proceso penal, esto es que "omnis praessumitur bonus nisi probetur malus, o lo que es lo mismo toda persona se presume buena a no ser que se pruebe mala" (Rodríguez Choconta, 2015, p. 69), es entonces en el cual entra el proceso penal, ya que es mediante este que se puede mostrar la prueba.

En este sentido, los sujetos procesales, mientras discurre el plazo para la audiencia de juicio mediante el procedimiento directo, hasta tres días antes de dicha audiencia, realizarán, por escrito, el anuncio de pruebas; pero de considerarlo necesario, en forma motivada de oficio o a petición de parte, el juzgador, puede suspender el curso de la audiencia, por una sola vez, indicando el día y hora para su continuación, la que no podrá exceder de quince días de la fecha de su inicio. El procedimiento directo resulta factible a partir de la audiencia de calificación de flagrancia, pero que contiene un defecto procesal grave, porque se estaría desarrollando una acusación y posterior juicio sin que el procesado tenga claridad sobre la imputación formal que se le está haciendo. 
Se enfatiza en la Constitución de la República del Ecuador (2008) en su artículo, 1 determina, que el Ecuador es un Estado constitucional de derechos y justicia, hecho por el cual se garantiza entre otros, el respeto a los derechos humanos, a la igualdad formal y material, a la tutela judicial efectiva, imparcial y expedita, al debido proceso, a ser juzgado por un juez competente y a la seguridad jurídica; se determina además que el proceso penal es un medio para la realización de la justicia.

Por lo tanto, es necesario mencionar, que algunas de las normas contenidas en el nuevo Código Integral Penal, propician una celeridad y una des formalización del excesivo ritualismo, en miras de conseguir y llegar hacia una justicia sin papeles, ni dilaciones que generen retardos injustificados, en donde la práctica podría resultar muy beneficiosa, debido a la agilidad en la resolución de los procesos, respetando las garantías que forman parte de nuestro bloque de constitucionalidad, y a nivel de tratados internacionales.

Sin embargo, la aplicación del procedimiento directo, causa graves violaciones a los derechos constitucionales, por lo que genera una inseguridad jurídica, no existe una plena tutela judicial efectiva de los derechos, y sobre todo se viólela un derecho fundamental como es el derecho a la defensa del cual goza todas las personas. La falta de tiempo con el que se cuenta a fin de obtener pruebas fehacientes, es la que generan incertidumbre, por lo que no se ve en la factibilidad que en diez días se practiquen todos las diligencias tendientes a la obtención de pruebas, mismas que se deberán anunciar tres días antes de la audiencia de juzgamiento, es por ello que se vulnera la legitima defensa, el derecho fundamental e inherente al hombre como es de la defensa, y realmente es imposible obtener y realizar diligencias en diez días, por lo que varios delitos quedan en la impunidad, o a su vez la titular de la acción pública (Fiscalía), encuadra una conducta en otro tipo penal diferente.

\section{FINANCIAMIENTO}

No monetario. 


\section{AGRADECIMIENTO}

A la Universidad Regional Autónoma de los Andes, Ibarra, por motivar el desarrollo de la Investigación.

\section{REFERENCIAS CONSULTADAS}

Asamblea Nacional Constituyente de la República del Ecuador, (2008). Constitución de la República del Ecuador. [Constitution of the Republic of Ecuador]. Montecristi. Registro Oficial 449 de 20-oct-2008. Recuperado de https://n9.cl/sia

Asamblea Nacional de la República del Ecuador (2014) Código Orgánico Integral Penal. [Comprehensive Criminal Organic Code]. Ley 0 Registro Oficial Suplemento 180 de 10-feb.-2014 Ultima modificación: 17-feb.-2021. Quito. CEP. Recuperado de: https://n9.cl/w5nul

García Falconí, J. C. (2009). Los principios rectores y disposiciones fundamentales que se debe observar en la administración de justicia en el Ecuador según el Código Orgánico de la Función Judicial. [The guiding principles and fundamental provisions to be observed in the administration of justice in Ecuador according to the Organic Code of the Judicial Function] Quito, Ecuador: Ediciones Rodin. Recuperado de: https://n9.cl//zgfm

Pérez, A. J., \& Cruz, M. (2016). La prueba y la presunción de inocencia en el código orgánico integral penal. [Proof and the presumption of innocence in the comprehensive organic penal code]. (Primera ed.). Quito-Ecuador: Latitud Cero Editores.

Rodríguez, O. (2015). Presunción de inocencia, Principios Universales [Presumption of Innocence, Universal Principles]. (Tercera ed.). Bogotá-Colombia: EDICIONES DOCTRINA Y LEY LTDA.

Roxin, C. (2003). Derecho Procesal Penal. [Criminal Procedural Law]. 1a. Ed. Buenos Aires, Editores del Puerto. Recuperado de: https://n9.cl/c95zo 